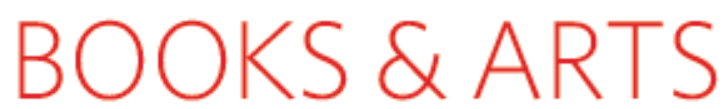

\title{
Diversity and controversy
}

\section{Why did a well-intentioned effort to understand human evolution go so wrong?}

Race to the Finish: Identity and Governance in an Age of Genomics

by Jenny Reardon

Princeton University Press: 2005. 312 pp.

$\$ 55, € 35.95$ (hbk)/\$17.95, $€ 11.95$ (pbk)

\section{Diane Paul}

The Human Genome Diversity Project had a short and troubled life. The aim was to sample and preserve DNA from "isolated indigenous

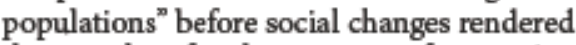
them useless for the purpose of answering questions about human evolution. But from its birth around 1991 to its unofficial death less than a decade later, indigenous-rights groups attacked the project as racist and neocolonialist, branding it the 'Vampire Project.' The effort ultimately became an embarrassment to its funders. Today, research on human genetic variation flourishes, but under other rubrics and largely under the radar of Diversity Project critics.

As Jenny Reardon stresses in her book Race to the Finish, the project's leaders were well-intentioned and had impeccable antiracist credentials. So why did their effort draw unremitting hostility from groups representing indigenous peoples, some physical anthropologists and others? And could the critics' fears have been allayed without gutting the project?

As Reardon tells it in this engrossing and even-handed book, the scientists never knew what hit them, and so were unable to mount a response to the project's detractors. The scientists involved believed they were in a race against time to answer compelling questions about human origins and migrations. But the peoples on whose cooperation the project depended - or at least those claiming to speak for them - were not interested in the scientists' questions about human origins (to which they already had satisfying answers), disliked being thought of as a resource, took umbrage at the assumption that they were vanishing, mistrusted the project leaders' motives, especially in regard to patent issues and, in general, did not see what was in it for them.

The organizers struggled to comprehend this reaction. A politically progressive and socially sensitive lot, they knew they were not out to make money, but to pursue what in their view was important and urgent research. To be tarred with the brush of racism - especially

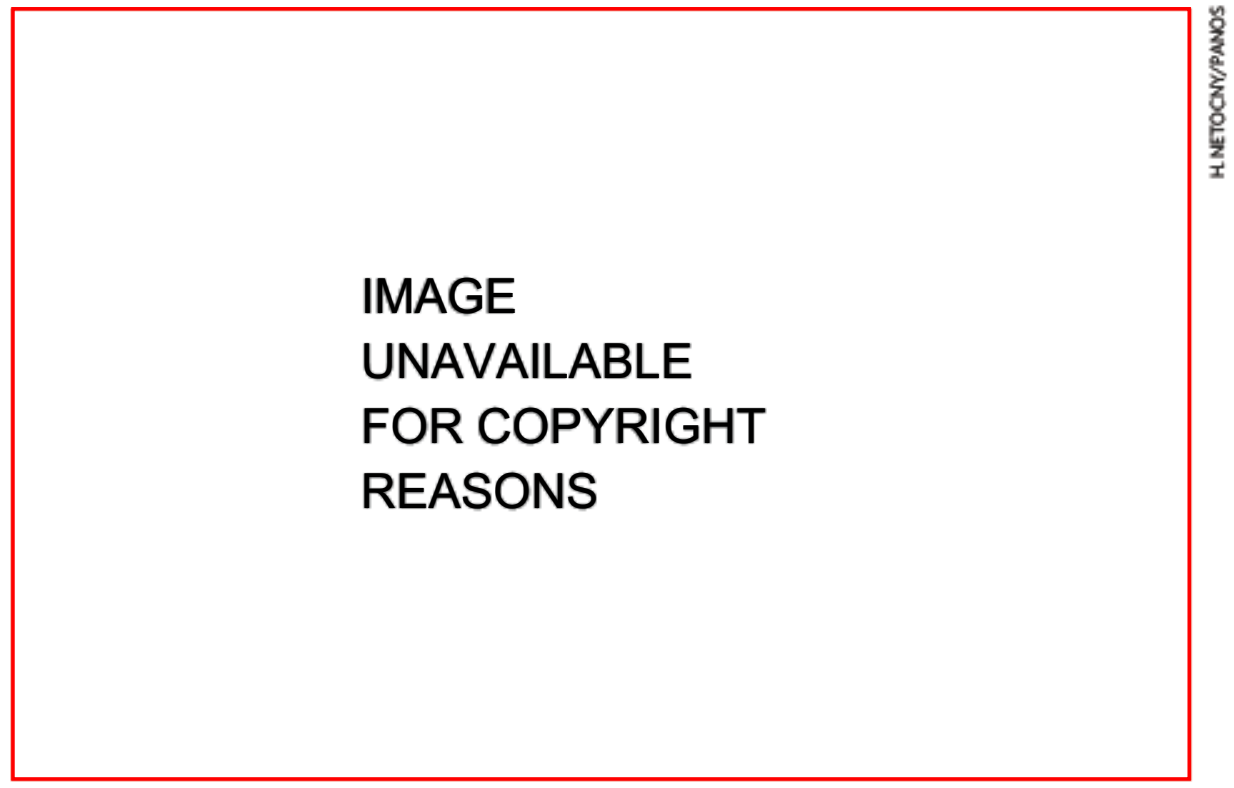

Researchers facedopposition to their plans to understand the origin of indigenous peoples.

given their personal histories - must have been galling. Luigi Luca Cavalli-Sforza had been a trenchant critic of William Shockley's claim of black genetic inferiority; Robert Cook-Deegan had a long record of involvement with Physicians for Human Rights, and Mary Claire King had worked with the grandmothers of the Plaza de Mayo to identify children kidnapped during Argentina's dirty war. But avowals of their good intentions did not mollify critics, and organizers eventually set about addressing specific concerns.

Unfortunately, in trying to solve one problem, they often created another. For example, in addressing concerns over whether subjects could give truly informed consent, organizers drafted a model ethical protocol incorporating the innovative concept of group consent. But, in a particularly rich chapter, Reardon shows that instead of alleviating worries, it ultimately prompted new concerns about paternalism and the revival of old colonialist and racist categories.

In trying to respond to criticism and build legitimacy for the project, the evolutionary biologists and population geneticists who launched it constantly widened the circle of those consulted. Anthropologists and bioethicists were brought into the fold. But those who felt excluded wanted to speak for themselves.
In time, indigenous-rights organizations, African-Americans and Native Americans were also invited to join the discussion, raising some thorny questions about the identity of groups and who was authorized to speak for them.

In any case, these groups were themselves divided and so were impossible to enrol as a unit. Thus there were both supportive and critical voices within anthropology - the most fractured of disciplines - and although some African-Americans and Native Americans were attracted to opportunities offered by the project, others feared co-option and saw efforts to include them as bribes. For some opponents, to even critique a proposal would grant it legitimacy.

Could the project have been saved? Reardon believes that it might have been had discussion gone much deeper, with sustained attention to questions of the nature of scientific knowledge and its relation to power. It seems that the moral of the story is the need to include scholars from the field of science studies, who could have introduced a more sophisticated framework for thinking about race and power in genetic research. Perhaps. But it may be that even then a solution that satisfied critics while preserving the project's core was simply unachievable.

In the event, the critics stopped the project 
in its tracks. Reardon sees little to celebrate in this victory. The project's proponents correctly predicted from the start that, if they failed, the research would continue but in a much less public and organized way. The study of human genetic variation is now fashionable, but it is being pursued without scrutiny of the deeper issues that Reardon believes essential to the pursuit of both a more reflective science and a more sensitive society. Funders have understandably tried to avoid the controversies that sank the Diversity Project. But the ironic result has been to narrow discussion of the issues at stake even further.

Diane Paul is in the Department of Political

Science, University of Massachusetts, 100 Morrissey Boulevard, Boston, Massachusetts 02125-3393, USA.

\section{Touching a nerve}

\section{The War of the Soups and the Sparks: The Discovery of Neurotransmitters and the Dispute over How Nerves Communicate by El liot S. Valenstein \\ Columbia University Press: 2005. 256 pp. $\$ 31, £ 19.50$}

\section{Charles Stevens}

Controversy is an inevitable, and essential, part of science, but one that scientists generally find uncomfortable and tend to regard as a blemish to be hidden from the public. Elliot Valenstein's book The War of the Soups and the Sparks is a readable and instructive history of one of neuroscience's most important scientific disputes, the three-decade debate about how neurons communicate with one another. He explains the way our current views developed and places the work in its social and human context by providing biographical sketches that bring the participants to life.

One neuron sends information to another at a point of contact known as a synapse. We now understand this process of information transfer in great detail, and know that it involves the release of a chemical, called a neurotransmitter. Valenstein's book is about how we arrived at this picture, and especially about the controversies along the way. The main debate related to whether synaptic transmission is chemical - that is, whether the informationcarrying signal is the release of a neurotransmitter - or whether it, like the nerve impulse itself, uses purely electrical signals.

The story begins about a hundred years ago with investigations of how nerves influence the function of organs; an example is the slower heart beat produced by stimulating the vagus nerve. By 1920 it was firmly established, largely by Henry Dale, that acetylcholine, a chemical not known at the time to occur in the body, also decreased the heart rate and duplicated various effects of nerve stimulation on other organs. But the idea that the vagus nerve secreted acetylcholine or something similar was not considered: nerves are tiny, seemingly too small to be the source of hormone-like chemicals.

Starting in 1921, Otto Loewi published a series of papers claiming that the vagus nerve secretes some chemical - he called it Vagusstoff - when stimulated, which slows

\section{IMAGE UNAVAILABLE FOR COPYRIGHT REASONS}

A stimulating debate: Henry Dale (top) and Otto Loewishowed thatnerves release chemicals. the heart. Loewis work met with great scepticism, partly because he could not show that the Vagusstoff came from the vagus nerve and not the heart, but mainly because others could not repeat his technically tricky experiments. Using improved techniques, Dale identified the Vagusstoff as acetylcholine and showed that it was released by the stimulation of many different nerves that affect the function of various organs. By 1936 the conclusion that neurotransmitter is released at synapses outside the brain was well enough established to attract a Nobel Prize for Loewi and Dale.

In 1936, physiologists could accept that the neurotransmitter released by the vagus nerve slows the heart and has other slowly develop- $\vec{s}$ ing effects. But they could not believe that this mechanism could cause rapid events such as the contraction of skeletal muscle or communication in brain circuits. Instead, they were convinced that this must be due to a direct spread of current from nerve impulses, known to involve electrical rather than chemical signals.

Almost all neurophysiologists believed that synaptic transmission had to be electrical, rather than chemical. One of the most prominent opponents of chemical transmission for fast synapses was John Eccles, a friend and great admirer of Dale. Their debate was vigorous, but good-natured and respectful. Valenstein points out that the physiologists believed that only electrical transmission could be fast enough, but also that the dispute was a class war between pharmacology and physiology. The physiologists used modern, sophisticated methodology and tools, such as the cathoderay oscilloscope, whereas pharmacologists were still using bioassays, such as leech muscle, and old-fashioned recording methods. The physiologists looked down on the pharmacologists, and felt that conclusions based on methods less sophisticated than their own were not to be trusted.

This dispute continued until the middle of the twentieth century, when results from new technology finally convinced the physiologists that synapses do communicate by the release of neurotransmitters. Eccles, one of the strongest proponents of electrical transmission at synapses, provided some of the key evidence showing that he, and the other physiologists, had been wrong.

Why did this argument last so long? As with all such disputes, part of the reason was that technology was not available that could provide decisive tests of the alternative possibilities; the correct answer came with technological advances. The other reason is that synaptic transmission is much more complex than either side envisaged, and the discussion was framed in simplistic terms because the scientists involved sought simplicity where it did not exist.

Charles Stevens is at the Salk Institute for Biological Studies, PO Box 85800, San Diego, California 92186-5800, USA. 